\title{
Building resiliency: a cross-sectional study examining relationships among health-related quality of life, well-being, and disaster preparedness
}

Monica E Gowan ${ }^{1 *}$, Ray C Kirk ${ }^{2 \dagger}$ and Jeff A Sloan ${ }^{1+}$

\begin{abstract}
Background: Worldwide, disaster exposure and consequences are rising. Disaster risk in New Zealand is amplified by island geography, isolation, and ubiquitous natural hazards. Wellington, the capital city, has vital needs for evacuation preparedness and resilience to the devastating impacts and increasing uncertainties of earthquake and tsunami disasters. While poor quality of life (QoL) is widely-associated with low levels of engagement in many health-protective behaviors, the relationships among health-related quality of life $(\mathrm{HrQOL})$, well-being, and preparedness are virtually unknown.

Methods: We hypothesized that QoL and well-being affect household evacuation preparedness. We performed a quantitative epidemiologic survey (cross-sectional design) of Wellington adults. Our investigation assessed healthpromoting attributes that build resiliency, conceptualized as health-protective attitudes and behaviors. Multidimensional QoL variables were measured using validated psychometric scales and analyzed for associations with evacuation preparedness, and we determined whether age and gender affected these relationships.

Results: We received 695 survey responses (28.5\% response rate; margin of error $\pm 3.8 \%$; $80 \%$ statistical power to detect true correlations of 0.11 or greater). Correlational analyses showed statistically significant positive associations with evacuation preparedness for spiritual well-being, emotional well-being, and life satisfaction. No associations were found for mental health, social well-being, or gender; physical health was weakly negatively associated. Evacuation preparedness increased with age. Regression analyses showed that overall health and well-being explained 4.6-6.8\% of the variance in evacuation preparedness. Spiritual well-being was the only QoL variable that significantly and uniquely explained variance in preparedness.

Conclusions: How well-being influences preparedness is complex and deeply personal. The data indicate that multidimensional readiness is essential, and meaningfulness is an important factor. Inadequate levels of tangible preparedness actions are accompanied by gaps in intangible readiness aspects, such as: 1) errors in perceived exposure to and salience of natural hazards, yielding circumscribed risk assessments; 2) unfamiliarity with the scope and span of preparedness; 3) underestimating disaster consequences; and 4) misinterpreting the personal resources required for self-managing disaster and uncertainty. Our results highlight that conceptualizing preparedness to include attitudes and behaviors of readiness, integrating well-being and meaningfulness into preparedness strategies, and prioritizing evacuation planning are critical for resiliency as a dynamic process and outcome.
\end{abstract}

Keywords: Earthquake, Evacuation, Hazards, Health promotion, Health outcomes, Prevention, Integrative disaster resilience, Risk perception, Self-management, Tsunami

\footnotetext{
* Correspondence: monica.gowan@gmail.com

${ }^{\dagger}$ Equal contributors

'Department of Health Sciences Research, Mayo Clinic, 200 First St SW,

Rochester, MN, USA

Full list of author information is available at the end of the article
}

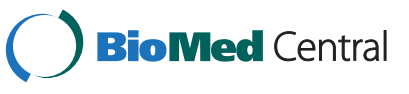

(c) 2014 Gowan et al.; licensee BioMed Central Ltd. This is an Open Access article distributed under the terms of the Creative Commons Attribution License (http://creativecommons.org/licenses/by/4.0), which permits unrestricted use, distribution, and reproduction in any medium, provided the original work is properly credited. The Creative Commons Public Domain Dedication waiver (http://creativecommons.org/publicdomain/zero/1.0/) applies to the data made available in this article, unless otherwise stated. 


\section{Introduction}

Life-threatening and life-changing natural disasters are prevalent throughout the Pacific Rim and Indian Ocean area. Asia-Pacific leads the world with the greatest number of disasters, highest associated mortality, and greatest economic losses this millennium [1]. New Zealand is a heightened disaster "riskscape" [2] because of its isolated location (roughly $1,500 \mathrm{~km}$ east of Australia), over $15,000 \mathrm{~km}$ of coastline, small landmass $\left(<270,000 \mathrm{~km}^{2}\right)$, and omnipresent vulnerability to natural hazards [3-5], including seismic hazards arising from local, regional, and trans-Pacific sources [6-8].

In fact, a complex, long-lasting series of damaging earthquakes (the "Canterbury earthquake sequence") with extremely high ground motions [9-11] struck Christchurch and the Canterbury Region of New Zealand's South Island over a 2-year period during the tenure of this study, claiming scores of lives [12]. An estimated 900 commercial buildings in the central business district and more than 30,000 residential properties were declared total losses $[13,14]$. Tens of thousands were forced from their homes and workplaces [15]. These events strained utility infrastructure [16] and the health sector response capacity $[17,18]$ and dramatically affected the national economy $[19,20]$. Seismicity is ongoing in Canterbury [9] and elsewhere in New Zealand; strong earthquakes struck the Wellington and Marlborough Regions (the "Cook Strait Earthquakes") in mid-2013 and the Wellington and Manawatu-Wanganui Regions (the "Eketahuna Earthquake") in early 2014 [21].

The coastal, capital city of Wellington, the geographic focus of this investigation, has a long history of earthquakes and tsunamis [22,23]. Most of the regional population and the nation's governance are vulnerable to these seismic threats [24]. In addition to mass casualties [25], damage to homes, utilities, services, and the economy could result in mass evacuations and extreme hardship [26-28] from the national to household level.

Devastating earthquakes and tsunamis also profoundly and persistently affect human health [29] and quality of life (QoL) [30,31]. Poor psychological and economic well-being can induce cognitive disruption [32,33] and prolong recovery from deep hardship by creating comorbid and chronic health effects [33-37]. Dislocation and internal displacement can induce disorientation and disconnection [38], and evacuees may have up to twice the rate of illness than nonevacuees affected by disaster [39].

Disasters are thus ultimately health outcomes, a function of how people are affected by or respond to the ambient riskscape. As in preventive medicine, adverse disaster outcomes therefore are somewhat preventable. Although avoiding natural hazards may be impossible, preparation can reduce vulnerabilities and minimize exposures to calamitous outcomes $[40,41]$.
Evolving paradigms in disaster management and research Disaster risk reduction (DRR) [42] focuses on building an engineering and systems-wide capacity for dynamic adaptation [43] through risk management. DRR is often equated with minding the risk and, often by extension, resilience. The meaning of resilience, however, is evolving with time and application [44-46]. We argue that minding the risk and resilience go beyond managing hazards, vulnerability, and exposure; a framework for self-managing consequences is essential [46,47]. Extreme events require robust decision-making capacities and deep personal resources, especially when displacement unexpectedly occurs $[48,49]$. Moreover, people differ in how they perceive and process their risks affectively and cognitively [50,51].

We conceptualize disaster resilience as a process and outcome that embodies disaster prevention. We consider personal resiliency to be a dynamic and multidimensional state of well-being and readiness that manifests as a fundamental awareness ("the threat is present"), acceptance of potential loss ("it can happen to me"), empowering, protective attitudes ("I have resources and choices"), and engagement in preventive actions ("I am actively building personal resources and adaptive capacities"). By cultivating well-being and intentionally engaging in preparedness, readiness becomes more than risk management; it is an integrative, fluid, and healthpromoting state ("I am as well as I can be") that facilitates adaptive postdisaster trajectories [52,53]. This state of positive health can be available and accessible, regardless of external circumstances [54].

Preventing disaster by reducing risks and enhancing protective processes is now a global priority [55-57]; the United Nations currently proposes to name the post2015 framework for disaster risk reduction "Managing Risk to Achieve Resilience." These needs are recognized by New Zealand civil defense and emergency management [58], and Wellington recently was named 1 of 10 partner cities worldwide for the City Resilience Profiling Programme under the United Nations Human Settlements Programme [59].

Historically, disaster research in the biomedical and social sciences has largely targeted risk reduction via the traditional focus on disease and diminished capacities; for example, the role of specific vulnerabilities or risk factors and their pathogenic relationships with morbidity and mortality (risk/deficit approach) have been examined $[37,60,61]$. Research has also addressed the amplification of vulnerability among those with chronic disease and disability [62-64]. Appropriately, previous work in promoting disaster preparedness has focused strongly on overcoming medical, social, and demographic barriers to preparedness actions [40,65-67].

However, resiliency research increasingly uses a biopsychosocial model (strength/asset approach) [68-70] to 
evaluate the influence of health-enhancing or protective factors (health management resources) on recovery trajectories [71-73]. Indeed, multidimensional, salutogenic (wellness) paradigms $[74,75]$ have long been harmonious with definitions from the World Health Organization (WHO) for health and QoL $[76,77]$. They are also consistent with research findings showing that altruistic and existential attitudes, intrinsically motivated goals, and salutary behaviors support growth and build resiliency after traumatic events [78-80]. Further, they are complementary with research into the cognitive and social processing of preparedness messages [48-51], the effect of experience on hazard adjustments [81], current models of protective action decision-making [48], and an emerging shift toward a health-promoting, community-level emphasis on "what to do about risk" [82].

\section{Need to strengthen the evidence base}

A compelling need remains for evidence-based research [82-87]. In New Zealand, national baseline data on health, QoL, well-being, and emergency preparedness can be used to determine the status of health management resources and capacity for resiliency-building at the population level [88-92]. Nevertheless, associations among QoL and wellbeing (health-protective attitudes) and disaster preparedness (health-protective behavior) are unknown, and only one study has examined the role of quality of life in disaster preparedness [93]. To our knowledge, relationships between these affective and behavioral constructs are unexplored elsewhere, nor have they been evaluated in the context of earthquake or tsunami evacuation.

We assessed the prevalence of health-related QoL (HrQoL) and global life satisfaction (subjective well-being) by using validated psychometric instruments and measured the level of engagement in disaster preparedness, with a specific focus on evacuation preparedness. We determined associations among domains of well-being and preparedness behaviors and also collected data on cognitive and affective risk perceptions for earthquake and tsunami disaster. Our results expand the evidence base on QoL and well-being to support efforts to 1) meet emergency management needs in Wellington and 2) promote continued and effective resiliency-building in all communities at risk.

\section{Methods}

We hypothesized that adults with higher quality of life will exhibit higher levels of household preparedness for earthquake and tsunami. We developed measureable attributes of resilience by examining QoL constructs and operationalizing selected indicators of multidimensional well-being and disaster preparedness. The framework [94-99] used to assess health management resources is presented in Table 1. We selected a cross-sectional design, with a random sample drawn from the general adult population. We used a quantitative epidemiologic survey instrument to measure the prevalence of and relationships among key variables. The survey contained 56 questions obtained or derived from validated psychometric scales and QoL instrument databases [100,101], social science surveys on disaster in New Zealand, Australia, and the United States [102-105], and questions developed specifically for this study; demographic questions from the New Zealand census also were included [106]. Ethics notifications and approval were obtained from the Human Ethics Committees at Massey University and the University of Canterbury.

Administrative economy dictated a multistage cluster sampling plan. An area-based sampling frame was selected within an isolated physiographic region of eastern Wellington (Figure 1). This area, located east of the Wellington Fault, has a broad range of natural hazards (e.g., earthquake, tsunami, seiche, liquefaction, landslide, and wildfire). The potential for disruption of public utilities and loss of road access is high after a Wellington Fault earthquake [24-28], and the need for spontaneous or mandatory mass evacuations and domestic displacement from earthquake and tsunami [28,107-109] is conceivably greater here than elsewhere in Wellington.

A sample of 6 suburbs from the area-based frame was selected as the accessible population. Collectively, they encompassed various geographic, geologic, and socioeconomic conditions. A household was the unit of observation. The sample frame was all households within the boundaries of the 2006 Statistics New Zealand census maps for the 6 suburbs. The sample list was developed by using a systematic sampling interval plan of recording addresses for every other household on every street within the defined boundaries. Variations in accessibility (e.g., because of topography, building security, vacant or business properties) resulted in a final sampling interval of every second to third household and an accessible population of 2,451 residents. A probability sample was obtained for unit analysis of data at the level of 1 adult individual per household. Survey packets were posted in early November 2008 and the survey field period closed at the end of March 2009.

On-line sample size calculators [110] were used to determine the minimum recommended sample size for statistical similarity in population characteristics with a $\pm 5 \%$ margin of error at a $95 \%$ confidence level. These calculations showed a need for 384 survey respondents; assuming a $30 \%$ response rate, this would require posting surveys to 1,277 households. We increased the total sample to 2,451 households to ensure sufficient data.

Five validated psychometric scales were selected to represent HrQoL domains, consistent with the WHO definition of health and QoL [76,77]. Physical health status and mental health status were measured using the 
Table 1 Health Management Resources for Building Disaster Resiliency

\begin{tabular}{|c|c|c|}
\hline Construct & Domain or Category & Measure or Specific attribute \\
\hline \multicolumn{3}{|l|}{ Health-Protective attitudes ${ }^{a}$} \\
\hline \multirow[t]{5}{*}{ Health-related quality of life } & Physical health status & SF12 (v1) [94] \\
\hline & Mental health status & SF12 (v1) [94] \\
\hline & Emotional well-being & SOC13 [95] \\
\hline & Spiritual well-being & SS20 $[96,97]$ \\
\hline & Social well-being & FS [98] \\
\hline Global quality of life & Global well-being & SWLS [99] \\
\hline \multicolumn{3}{|l|}{ Health-Protective behaviors ${ }^{\mathbf{b}}$} \\
\hline \multirow[t]{16}{*}{ Earthquake and tsunami evacuation preparedness } & Talking about these events & With social network \\
\hline & & With neighborhood \\
\hline & Seeking information & Risks and consequences \\
\hline & & How to prepare \\
\hline & & How to respond \\
\hline & & How to evacuate \\
\hline & Making evacuation plans & Survival and escape \\
\hline & & Evacuation and dislocation \\
\hline & & Communication \\
\hline & Testing evacuation plans & Evacuation route \\
\hline & & Assembly area \\
\hline & & Participated in drill \\
\hline & Making disaster kits & Survival and escape \\
\hline & & Evacuation and dislocation \\
\hline & & Communication \\
\hline & & Kit accessible \\
\hline
\end{tabular}

Abbreviations: FS 6-item Friendship Scale, SF12 12-item Short Form Health Survey, SOC13 13-item Sense of Coherence scale, SS20 20-item Serenity Scale, SWLS 5-item Satisfaction With Life Scale.

a Defined as health-related quality of life and subjective well-being.

${ }^{b}$ Defined as disaster preparedness.

Short Form Health Survey, 12-Item, version 1 [94]. Emotional well-being was measured using the 13-item Sense of Coherence scale $[95,111]$. Spiritual well-being was measured using the 20-item Serenity Scale [96,97]. Social wellbeing was measured using the 6-item Friendship Scale [98]. Global well-being was measured to address the WHO-QoL component of life satisfaction [76], using the 5-item Satisfaction with Life Scale [99]. We also asked participants to rate the perceived value of their healthmanagement resources during a disaster evacuation on a 5 -point Likert scale in each of the $5 \mathrm{HrQoL}$ domains. To understand access to health care providers when selfmanagement capacity is exceeded, we asked if they saw a regular general practitioner on at least an annual basis.

Many activities can promote disaster preparedness and organically translate into effective readiness. We identified 16 preparedness actions for earthquake and tsunami evacuation and grouped these items into 5 progressive levels of readiness (Table 1). People rated their level of engagement for each activity on a 5-point Stage of
Change scale $[112,113]$. They were also asked to similarly rate their engagement in any other activity (unspecified) to increase their preparedness for any disaster type (presented as "other, please specify").

People were further invited to describe (using unrestricted text) the 3 items they considered most essential for their personal evacuation kit.

Respondents were asked about their perceptions of disaster risk (type of threat; frequency of thought; imminence of threat) in rank order response format. People rated (on 5-point Likert scales) the perceived likelihood of various direct effects (property, health, and safety) and indirect effects (day-to-day life) of an earthquake or tsunami and their level of concern for required evacuation. Perceived preparedness to evacuate the home was measured with a single rating question item. To enrich our understanding of prior exposure to disaster, we sought anecdotal information (using open-ended questions) about the type of disaster experienced, personal impact, and the type of coping resources that were most helpful. 


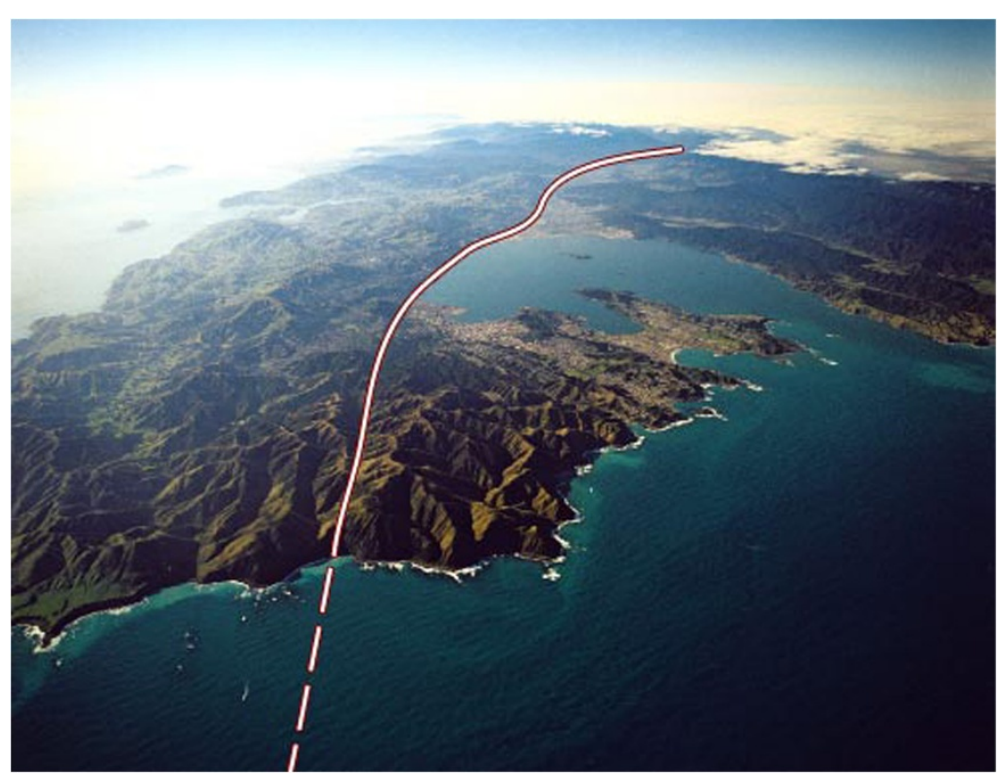

Figure 1 Aerial views of the Wellington Region, Lower North Island, New Zealand. The Wellington Fault is indicated by the dashed and solid line. The study area is to the east (right) of the Wellington Fault and consists of the elongate peninsula extending into Wellington's Inner Harbour and out into Cook Strait, the isthmus connecting the peninsula to the lower North Island, and the ridgeline that adjoins the isthmus. (Original photographic image by Lloyd Homer, with Wellington Fault overlay provided courtesy of Jim Cousins, PhD, and image license granted by Margaret Low, GNS Science, Lower Hutt, New Zealand. Used with permission).

After obtaining these descriptive data, we asked 3 questions:

1. Were scores on HrQoL and life satisfaction associated with scores on evacuation kit activity?

2. Were scores on QoL and evacuation kit activity significantly different when stratified by age and gender?

3. How well did scores on HrQoL and life satisfaction explain scores on evacuation kit activity?

We evaluated relationships between scores on HrQoL and life satisfaction and scores on evacuation kit activity by using correlation coefficients. We tested for significant differences in scores on QoL and evacuation kit activity due to the effects of age and gender by using the $t$ test, analysis of variance (ANOVA), or $\chi^{2}$ test, as appropriate. We used regression to determine how well HrQoL and life satisfaction scores explained scores on evacuation kit activity. For any proportion reported for the total sample, the results were accurate to within 3.8 percentage points with $95 \%$ confidence. For any mean reported for the total sample, results were accurate to within $3.8 \%$ of the standard deviation. For correlation coefficients calculated between 2 variables on the total sample, we had $80 \%$ power to detect a true correlation coefficient of 0.11 or greater. This was a small effect size [114], indicating that all but the smallest of correlation coefficients would be detected. Comparing 2 subgroups, equally split among 700 observations, provided a 2sample $t$ test with $80 \%$ power to detect a difference in mean scores of $21 \%$ times the SD (a small effect size [114]). It also provided an equality of proportions test with $80 \%$ power for a Fisher exact test to detect a difference of $11 \%$ between the proportions in each sample. The $\alpha$ level for all statistical tests was set at .05. No adjustment for multiple comparisons was made, given that this was an observational study and did not involve comparisons of control and intervention arms.

Qualitative string data were subject to content analysis, and responses were aggregated into summary categories and counts. They were subsequently tabulated and ranked from highest to lowest for all items selected by 10 or more respondents.

\section{Results}

We received 695 survey responses (response rate, 28\%). Age was normally distributed, with those aged 45 to 64 years making up the largest proportion (39\%). The majority of respondents $(62 \%)$ were women. The dominant ethnicity was New Zealand European (79\%). A majority (77\%) owned their home or were buying to live in it, had resided for more than 5 years in their suburb $(63 \%)$ and in their current residence (54\%), and lived in 1-family households (56\%). A majority (75\%) was employed at least part-time and had undergraduate (Level 7) degrees or higher (54\%). A minority (34\%) reported at least 1 dependent child. 
Most respondents identified earthquakes and tsunamis as the hazards most capable of requiring evacuation in the Wellington Region, far exceeding perceived threats from any other threat. Most people contemplated these seismic events at least a few times a year (earthquake, 48\%; tsunami, 58\%). Two percent never thought about an earthquake occurring, and $21 \%$ never thought about a tsunami. Eighty-two percent recognized that an earthquake could trigger a disaster in Wellington within 10 to 100 years; $24 \%$ identified that an earthquake disaster could be within the next year (imminent). Thirty-two percent understood that a tsunami disaster could transpire within 10 to 100 years; $19 \%$ realized it could be imminent.

At least 1 in 3 people believed they were very likely to be adversely affected by an earthquake or tsunami in the Wellington Region; this covered a broad spectrum of direct effects (damage or loss of property, 48\%; personal health and safety, 31\%) and indirect effects (daily activities, 50\%; mobility, 44\%; level of support available from friends and family, 32\%; income, 27\%; evacuation requirements, 27\%). Forty-five percent believed their property and daily life would be affected for more than 30 days. Twenty-one percent perceived that their health and safety would be affected for more than a month.

Eighteen percent perceived themselves as being well prepared for evacuation (Figure 2). Thirteen percent thought that their current preparedness plan would help a great deal. Fifty-six percent and 37\% reported they had taken (unspecified) action for earthquake and tsunami preparedness, respectively. Anecdotally, the top 3 items reported as essential for a personal evacuation kit were food, clothing or outerwear, and medications (Table 2).

Figure 3 shows the level of concern for evacuations; $24 \%$ had "a lot of concern" because of earthquake effects, and $17 \%$ shared a similar level of concern for tsunami evacuation. Eighty-eight percent of respondents had never evacuated for any reason. Seventy percent had no prior experience with earthquake or tsunami disaster, and 58\% had no prior experience with any other disaster type.

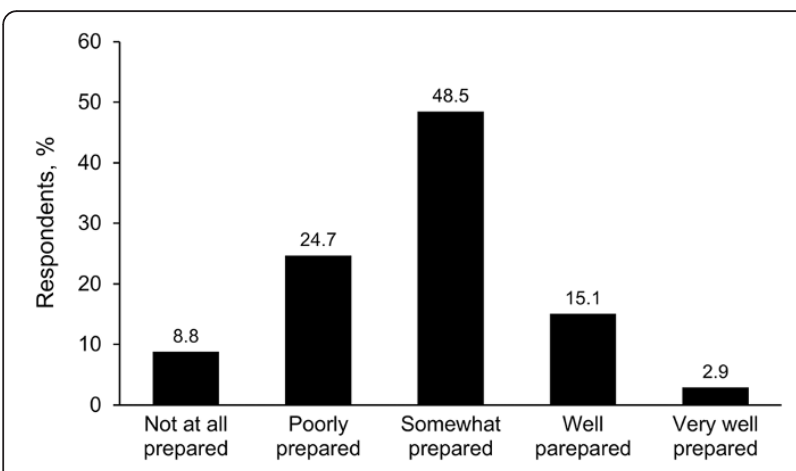

Figure 2 Perceived readiness for evacuation from home.
Table 2 Items Anecdotally Reported as Most Essential for Personal Evacuation Kit

\begin{tabular}{lc}
\hline Item & $\mathbf{n}$ \\
\hline Food & 118 \\
Clothing, outerwear & 95 \\
Medications & 88 \\
Documents, identification, wallet & 47 \\
Medical supplies and devices & 45 \\
Water & 27 \\
Footwear & 26 \\
Cell phone & 26 \\
Family & 25 \\
Radio & 16 \\
Blankets, insulation, sleeping bag & 11 \\
Pets & 10 \\
\hline
\end{tabular}

No personal health resource was perceived by a majority as helping a great deal with disaster evacuation (Figure 4). For those with prior disaster experience, however, social network support was anecdotally reported as the most helpful resource for coping with the disaster by a margin of $50 \%$ over mental and emotional support combined; only 1 person identified physical health as the factor that helped the most.

Eighty-eight percent of respondents reported having at least annual visits with a general practitioner. Overall, we observed that the study population showed positive health and well-being (Table 3); compared with global population norms [115-120], people reported higher levels of wellbeing in every domain of HrQoL and global well-being. Only small to moderate differences in mean QoL scores were found among age groups, and small differences in mean QoL scores were found between genders.

We observed modest differences in evacuation kit activity within age groups, with those aged 18 to 24 years least likely to prepare and those 65 and older most likely to prepare. A $X^{2}$ test for independence confirmed that age and

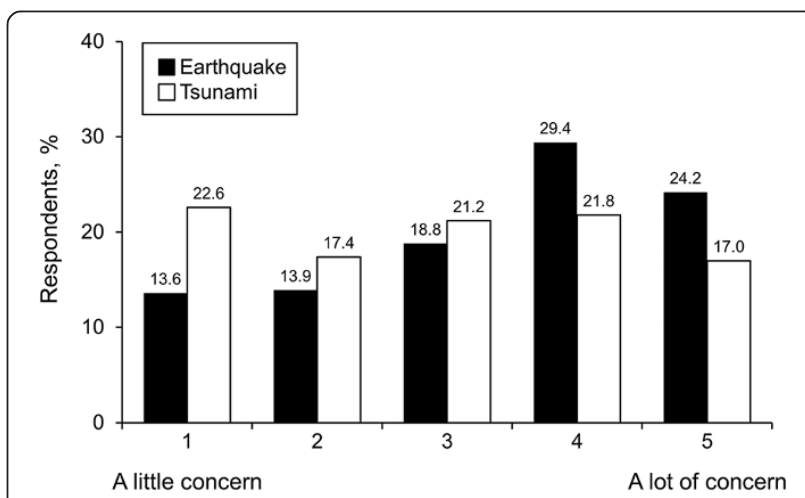

Figure 3 Level of concern for required evacuation. 


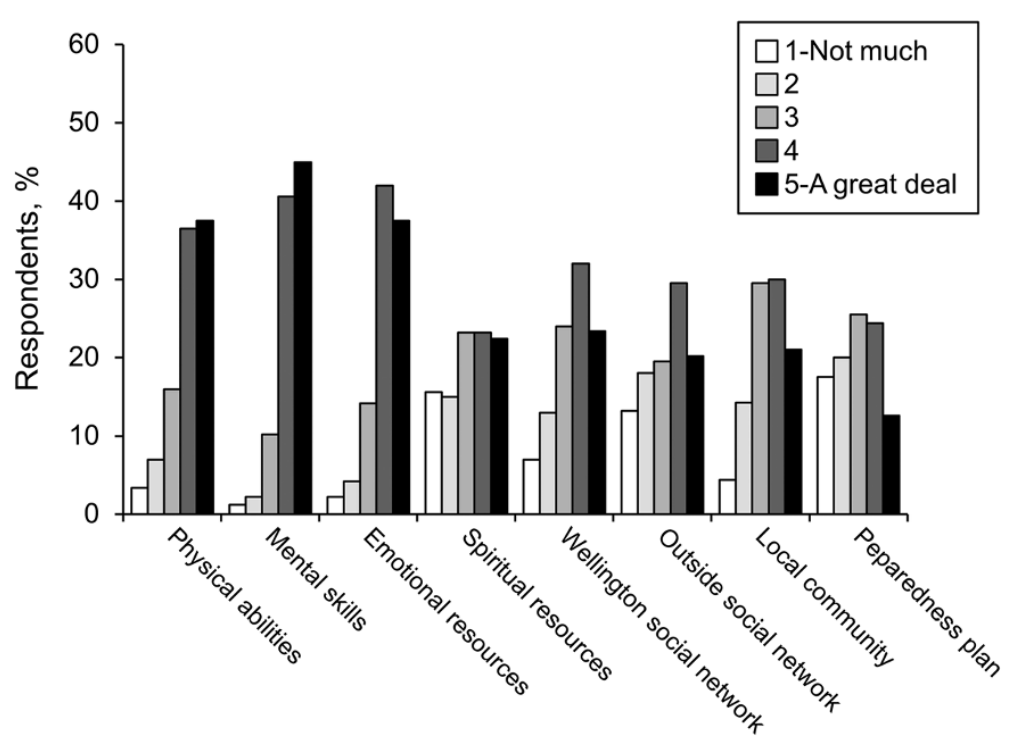

Figure 4 Perceived value of personal resources for coping with evacuation.

kit activity status were significantly associated, with a medium effect size, $\chi^{2}(3, \mathrm{n}=664)=18.028 ; P \leq .001$; Cramer's $\mathrm{V}=.165$. The strength of this relationship was moderate. A $\chi^{2}$ test for independence confirmed that gender and kit activity status were not significantly associated, $\chi^{2}$ $(1, \mathrm{n}=664)=.004 ; P=.95 ; \varphi=-.006$.

Examining the level of engagement in 16 preparedness activities (Table 1, health-protective behaviors), we observed slight differences between results observed at the Stages of Change level of measurement (Additional file 1: Table SA1) and under dichotomous conditions of intention vs action (Additional file 2: Table SA2). Figure 5 shows level of engagement in health-protective behaviors, stratified by intention vs action.

When examining relationships between mean QoL scores and evacuation kit activity, an independent samples $t$ test showed differences in scores when comparing those who did and did not engage in preparedness,

Table 3 Quality of Life in the Study Population

\begin{tabular}{lcccc}
\hline Quality-of-Life domain & \begin{tabular}{c} 
Possible \\
score, \\
\cline { 3 - 5 }
\end{tabular} & \multicolumn{2}{c}{ Sample score } \\
\cline { 4 - 5 } & range & Mean (SD) & Range \\
\hline Social well-being (FS) & $13-24$ & $20.4(4.0)$ & $3-24$ \\
Emotional well-being (SOC13) & $68.8(11.1)$ & $31-91$ \\
Spiritual well-being (SS20) & $20-100$ & $68.7(12.4)$ & $34-100$ \\
Physical health status (SF12 PCS) & $0-100$ & $50.2(9.4)$ & $16-67$ \\
Mental health status (SF12 MCS) & $0-100$ & $51.3(8.5)$ & $16-67$ \\
Global well-being (SWLS) & $5-35$ & $25.1(6.8)$ & $5-35$ \\
\hline
\end{tabular}

Abbreviations: FS 6-item Friendship Scale, SOC13 13-item Sense of Coherence scale, SS20 20-item Serenity Scale, SF12 12-item Short Form Health Survey, PCS physical component summary, MCS mental component summary, SWLS 5-item Satisfaction With Life Scale. although differences here were modest. The magnitude of the observed effect (effect size) was small for emotional (.013) and spiritual (.011) well-being (Table 4). Correlation analyses showed weakly positive, significant associations ( $\mathrm{r}=.10$ to .29 ) for the domains of spiritual and emotional well-being (Table 5). Social and global well-being had slightly smaller effect sizes and weaker associations, and no significant effect was found for associations among physical and mental health status and evacuation kit activity (Tables 4, and 5). Similar correlations were found for other types of kit activity at the dichotomous level of measurement. "Made a communications kit" had weakly positive associations with emotional well-being $(\mathrm{r}=.14)$ and spiritual well-being $(\mathrm{r}=.13)$. Likewise, "Made a survival kit" was associated with social well-being $(r=.13)$.

Within the 4 other categories of disaster preparedness (talking about earthquake or tsunami; seeking information about earthquakes or tsunamis; planning for disaster survival, evacuation, and communications; and testing evacuation plans), we observed weakly positive associations $(\mathrm{r} \leq .18)$ with QoL, whether examined at the Stages of Change level (Additional file 3: Table SA3) or under dichotomized conditions of intention and action (Additional file 4: Table SA4). Again, the domains of well-being that consistently showed significant relationships with preparedness were spiritual, emotional, and global well-being.

Standard and hierarchical multiple regression analyses indicated that QoL variables, with and without inclusion of life satisfaction, explained $3.3 \%$ to $4.2 \%$ of variance $(P<.01)$ in evacuation kit activity, as measured on the 5-level Stages of Change scale. Stepwise ordinary least squares regressions confirmed these results, with both models explaining $3.6 \%$ of variance in kit activity $(P \leq .001)$. When kit activity 


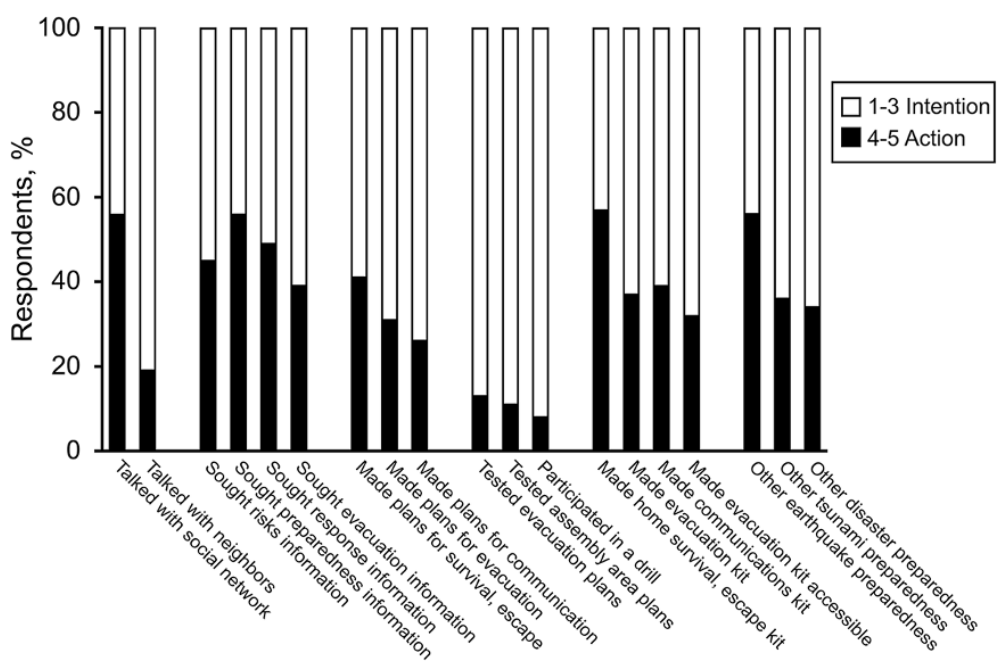

Figure 5 Level of engagement in disaster preparedness, stratified by intention vs action.

was dichotomized from 5 levels to 2 (intention vs action) and entered into a saturated logistic regression model, QoL variables explained from $4.6 \%$ to $6.8 \%$ of the variance $(P \leq .001)$. Stepwise logistic regressions provided results similar to the saturated logistic regression models $(4.1 \%$ $5.8 \% ; P \leq .001)$, predicting that about $94 \%$ to $96 \%$ of the sample was in a state of intention rather than action, as explained solely by QoL variables.

When the effects of age and gender were entered into the regression models, we observed a significant but very small increase in how well the model predicted kit activity. The model as a whole explained $4.1 \%$ of variance $(P \leq .001)$. When life satisfaction was added, variance increased slightly to $4.2 \%(P=.001)$. Age and gender explained $1.9 \%$ of variance in kit activity $(P=.002)$.

The strongest significant contribution to predicting kit activity was spiritual well-being (standardized regression coefficient $\beta=.112 ; P=.01)$. The only other significant (but negative) factor was physical health status $(\beta=-.085$;
$P=.04)$. Results were consistent when life satisfaction was included. In the hierarchical analysis, the strongest significant factors (with and without life satisfaction) were spiritual well-being $(\beta=.107 ; P=.01)$ and age $(\beta=.097 ; P=.03)$. In logistic regression, the only significant factors were spiritual well-being $(\beta=.015 ; P=.05)$ and age $(\beta=2.144$; $P=.006)$. When life satisfaction was included, only age was a significant contributor $(\beta=2.172 ; P=.005)$. In standard regression, spiritual well-being uniquely explained $1 \%$ of variance in kit activity. In hierarchical regression, spiritual well-being and age each uniquely explained less than $1 \%$ of the variance.

\section{Discussion}

This large, population-based study yielded a data set with robust, reliable, representative, and generalizable results $[88-92,121]$. The sample size provided solid statistical power for interpreting the significance and relevance of the data. The response rate and cross-sectional

Table 4 Mean QoL Scores by Domain, Stratified by Evacuation Kit Activity Status

\begin{tabular}{|c|c|c|c|c|c|c|c|}
\hline \multirow[b]{2}{*}{ Quality-of-Life domain } & \multirow[b]{2}{*}{ Possible score, range } & \multicolumn{2}{|r|}{ Intention } & \multicolumn{2}{|r|}{ Action } & \multirow[b]{2}{*}{$P$} & \multirow[b]{2}{*}{ Effect Size $^{b}$} \\
\hline & & n & Score, mean (SD) & n & Score, mean (SD) & & \\
\hline Social well-being (FS) & $0-24$ & 406 & $20.2(4.3)$ & 234 & $20.9(3.6)$ & .047 & .006 \\
\hline Emotional well-being (SOC13) & $13-91$ & 410 & $67.8(11.3)$ & 240 & $70.4(10.2)$ & .004 & .013 \\
\hline Spiritual well-being (SS20) & $20-100$ & 401 & $67.6(12.8)$ & 239 & $70.4(11.4)$ & .006 & .011 \\
\hline Physical health status (SF12 PCS) & $0-100$ & 403 & $50.6(9.1)$ & 239 & $49.7(9.6)$ & .23 & .000 \\
\hline Mental health status (SF12 MCS) & $0-100$ & 403 & $51.0(8.6)$ & 239 & $51.9(8.1)$ & .19 & .000 \\
\hline Global well-being (SWLS) & $5-35$ & 407 & $24.7(6.8)$ & 245 & $25.8(6.7)$ & .03 & .007 \\
\hline
\end{tabular}

Abbreviations: FS 6-item Friendship Scale, SOC13 13-item Sense of Coherence scale, SS20 20-item Serenity Scale, SF12 12 -item Short Form Health Survey, PCS physical component summary, MCS mental component summary, SWLS 5-item Satisfaction With Life Scale.

${ }^{a}$ Independent samples were compared by using a 2-tailed $t$ test.

${ }^{\mathrm{b}}$ Eta squared. Eta-squared is the proportion of total variation of the QOL domain attributable to the activity status. Guidelines for interpreting how much variance in kit activity can be accounted for by the scores from each $\mathrm{QOL}$ domain, and the importance of this effect size, are measured on a scale of $0=$ no effect; $.01=$ small effect; $.06=$ moderate effect; $.14=$ large effect; 1 = perfect effect [114]. 
Table 5 Relationships Among QoL Domains and Evacuation Kit Activity Status

\begin{tabular}{lccccc}
\hline & & \multicolumn{2}{c}{ Stages of change } & \multicolumn{2}{c}{ Dichotomized } \\
\cline { 3 - 6 } Quality-of-Life domain & $\mathbf{n}$ & Pearson $\boldsymbol{r}$ & $\boldsymbol{P}$ Value $^{\mathbf{a}}$ & & Pearson $\boldsymbol{r}^{\boldsymbol{P} \text { Value }}$ \\
\hline Social well-being (FS) & 640 & .07 & .08 & .08 & .06 \\
Emotional well-being (SOC13) & 650 & .12 & .002 & .11 & .005 \\
Spiritual well-being (SS20) & 640 & -.08 & $<.001$ & .11 & .006 \\
Physical health (SF12 PCS) & 642 & .07 & .04 & .05 & .05 \\
Mental health (SF12 MCS) & 642 & .07 & .08 & .08 & .19 \\
Global well-being (SWLS) & 652 & & .08 & .03 \\
\hline
\end{tabular}

Abbreviations: FS 6-item Friendship Scale, SOC13 13-item Sense of Coherence scale, SS20 20-item Serenity Scale, SF12 12-item Short Form Health Survey, PCS physical component summary, MCS mental component summary, SWLS 5-item Satisfaction With Life Scale. ${ }^{\text {a}}$ Two-tailed.

nature of the study mandates that our findings be interpreted with care, and with appreciation of the epidemiologic and statistical axiom that "correlation does not imply causation".

In summary, the data showed that Wellingtonians enjoy positive health and well-being, yet evacuation readiness was not prevalent. Associations between wellbeing and disaster preparedness were weak, but significant positive associations were observed for the domains of emotional and spiritual well-being and for life satisfaction. This fits within theoretical frameworks of QoL and salutogenesis that suggest health-protective attitudes and behaviors are positively related and that meaningfulness is a pivotal motivator [52-54,115,116].

Our finding that the majority of Wellington adults rated their overall QoL positively in each domain of well-being was an encouraging but perhaps unsurprising result. New Zealanders previously reported higher mean scores within physical and mental health domains compared with Australian and American populations [117-120], and the health status of Wellingtonians in our study was consistent with findings from recent national surveys [88-92]. Social well-being was further consistent with recent Australasian studies [118]. Levels of spiritual well-being were similar to means observed in other Wellington-based studies [96,97]. Emotional well-being was slightly greater than globally observed means $[115,116]$. Life satisfaction was as high or higher than means observed in developed countries $[99,119,120]$. The positive, health-oriented culture of New Zealand, with an emphasis on QoL, could have had a role in these results.

ANOVA indicated that the magnitude of the differences in mean QoL observed between age groups may not have any practical or theoretical significance. Differences (ie, the highest physical health and lowest mental health status in respondents 18-24 years old, and the converse for those aged 65 and older) are likely explained by the advantages of youth for positive physical health and the benefits of maturity toward all other domains of well-being. The slight degree to which gender was associated with higher mean QoL scores (higher mental health status in men, higher spiritual well-being in women) also may not have any significance. Within large sample sizes, some variance is natural, and even very small differences in groups can be statistically significant.

Notably, the data suggest that people generally were cognitively and affectively unprepared for a devastating earthquake and tsunami. This was a troubling discovery, further reinforced by our data indicating that half the survey respondents did not recognize the potential for being personally affected for greater than 30 days or even at all. The pervasiveness and persistence of these cognitive and affective gaps were underscored by data showing that only a small minority held considerable concern for evacuation due to earthquake (25\%) or tsunami (20\%) in this geographically isolated and exposed area. These outcomes were somewhat surprising, given that in the weeks preceding the field period for this study, a nationally broadcast television program (Aftershock, dramatizing an 8.2-magnitude earthquake and subsequent tsunami in Wellington [122]) received substantial media attention and public viewership. From a behavioral perspective, we emphasize that two-thirds had not made an evacuation plan, evacuation kit, or communications kit for earthquakes or tsunamis, and of those who had an evacuation plan, 90\% had not tested the plan or shared it with someone outside the region.

Furthermore, apparent misunderstandings of how to prepare emerged. For example, food, clothing, and essential medicines emerged as the top 3 items (anecdotally reported) that were essential for evacuation kits, but identity documentation, medical prescriptions, and legal and financial papers were ranked about $50 \%$ less frequently, even though they are commonly identified as critical components of getaway kits in New Zealand [123-125]. Food and clothing tend to be easily replaceable in developed 
countries, whereas documentation and functional aids can be more crucial and more difficult and stressful to reclaim, reconstruct, or reacquire.

Importantly, overall risk perception and preparedness in New Zealand are now at the highest levels to date [126-129] because of the 2013-2014 seismicity in central New Zealand, the 2010-2013 Canterbury earthquakes, and the 2011 Tōhoku, Japan, earthquake and tsunami. However, these data and our results both show that the predominant focus has been on home survival (sheltering in place) for earthquake, rather than evacuation readiness or displacement. This orientation could be due to a tacit assumption of what event a person is anticipating: to survive an initial geophysical shock followed by a limited number of days in isolation or short-term displacement, rather than prolonged recovery or permanent relocation. Indeed, it can be difficult to anticipate and act on the unthinkable realities and consequences of seismic disasters.

Resistance to preparing for evacuation, changing behavior, and challenges in evacuation decision-making have long been noted [49,130,131]. Preparedness gaps observed here may further reflect contradictions in perceived vs actual preparedness, how "preparedness" and "readiness" are individually defined, or overconfidence regarding anticipated responses to new experiences. Considerable evidence suggests a lack of awareness, skepticism, denial, and false optimism about earthquake disaster in the Wellington Region [132-136]. Results from our quantitative, randomized sample $(n=695)$ also are broadly comparable with findings from a qualitative study $(n=400)$ compiled from interviews obtained through convenience sampling, on tsunami awareness and evacuation preparedness in the Wellington Region [137].

Fortunately, gaps in evacuation planning are receiving greater attention worldwide [138-141]. In New Zealand, the Crown Ministries and emergency management offices are increasingly integrating more tsunami risk assessment, evacuation planning, and preparedness messaging in disaster studies and plans [8,107-109,142-145]. This is essential for appropriate public responses when there is little or no time for warning or when environmental conditions necessitate spontaneous or forced displacement.

Our results also show that the nature and extent of the relationships between resilient well-being and disaster readiness are more complex and heterogeneous than previously acknowledged. Although no association was observed with gender, the regression models did detect small to moderate differences among age groups, with those aged 18 to 24 years least likely to prepare and those 65 and older most likely to prepare. These effects may reflect an acceptance of mortality and altruistic beneficence that increases with age; we observed that among respondents aged 65 years and older, many indicated motivation stemming from their health limitations or for the benefit of their loved ones, descendants, or posterity. The amount of heterogeneity among individuals, in terms of the wellbeing domains most strongly associated with preparedness, was striking. When examined on a domain-by-domain basis using validated and reliable scales, we showed significant, positive associations between engaging in evacuation preparedness and spiritual well-being (serenity), emotional well-being (strong sense of coherence), and global wellbeing (satisfaction with life).

Because this study is a novel application of QoL scales to a pre-event preparedness context, direct comparison with previous research is impossible. However, a telephone survey conducted in 14 American states from 2006-2010 ( $\mathrm{n}=104654$ ), indicated that when comparing groups by the presence or absence of impaired physical and mental health and life satisfaction, those with impairments were more likely to have preparedness deficits [93]. Troubling gaps in evacuation readiness were also observed for those reporting physical and mental health impairments, and the authors highlighted a strong need for evacuation messaging [93].

Multiple studies of well-being and life satisfaction, conducted in the post-event context of various life adversities, strongly support our observations that different aspects of well-being are more salient and actionable at different ages and life circumstances and that all domains are important for overall positive health [80,146-151]. Further, perceived risk, HrQoL, and preparedness behavior often change organically after experiencing disaster, as do personal definitions of subjective well-being [152-155].

Prior disaster experience is likely to be among the strongest public motivators to prepare $[81,82]$. Post-disaster "windows of opportunity," for survivors and those who experience disaster vicariously through events in the media, also motivate preparedness typically within a two-year period $[82,156,157]$. Consequently, for sustained readiness it is imperative to address both the pertinent socialcognitive constructs of preparedness messaging $[48,81,82]$, and the decisional balance between intention and action that an individual encounters after receiving readiness cues $[112,113,150]$.

The most effective interventions tend to target these distinct yet complementary influences [158]; the adoption and maintenance of health behaviors requires both motivation and volition [159]. For example, a decision to prepare might be confirmed by the collective behavior of a person's social networks and community [48,82], but it also builds on the internal resolve a person has to create and act on intentions [80] - regardless of what other people are doing (or not doing).

Behavior is thus affected by and has an effect on multiple levels of influence $[160,161]$. Interventions that aim to affect the decisional balance to prepare - through 
personally-salient, intrinsically-motivating, and healthpromoting beliefs and processes - are needed to better understand the strength of this personal component in preparedness. They may be important not only for building preparedness, but also for maintaining sustained readiness and resilience beyond "the teachable moment."

Conducting an investigation is sometimes an intervention in itself, by raising self-awareness of what is personally important. In our own baseline data set, we observed disconnections between what people perceived as factors in their personal preparedness and what actually affected their preparedness actions. We note that the associations detected directly contrast with perceptions by the study population that physical and mental abilities are the most important QoL factors for disaster resilience and that spiritual resources are least helpful. Yet those respondents with personal disaster experience anecdotally reported that making meaning of the disaster and intentionally cultivating personal resilience helped them best cope. Although effect sizes are small, our quantitative data and analytic results were consistent with these anecdotal data.

Within the numerous explanatory models constructed to analyze our data set, overall QoL and well-being accounted for only $4.6 \%$ to $6.8 \%$ of the variability in evacuation preparedness, and spiritual well-being explained $2.2 \%$ of the variance. Although the latter is a small contribution, it was the strongest observed effect among all variables. Spiritual well-being may be an overlooked health-protective resource for building resiliency, effectively coping with adversity, and transforming the disaster experience into a meaningful or salutary life event.

There are many possible explanations for why the data showed these weak relationships. One is the presence of biases in risk perceptions [48-51,81,82,130-135]; the cognitive dissonance of logical inconsistencies abounds within our data set. These types of conundrums have been explored extensively by others to understand their etiology $[50,162]$, develop better survey instruments $[67,136]$, and improve risk communication strategies $[163,164]$. Secondly, as noted earlier, previous experience affects the frequency and structure of preparedness behavior $[156,157]$. Anecdotal reports by respondents indicated a significant number had survived a wide variety of prior disasters. Although many of these events cited dated to the mid- to late- $20^{\text {th }}$ Century, the insights shared suggest these events have left a strong imprint on their risk perceptions.

A third alternative explanation is that a single, overall predictive model of disaster preparedness seems unlikely to exist; rather, a plethora of factors most likely explains preparedness as a whole, and the small percentage of the variance in preparedness activity from QoL and wellbeing reflects deeply personal approaches to wellbeing. The more the study variables were isolated in the analyses here, the less powerfully an effect was observed with preparedness. A result is that there is no evidence for making specific adaptations for preparedness education based on one particular domain of well-being at the expense of the other. Disasters are complex problems, with complex solutions, and disaster resilience is dynamic, personal, subjective, and sometimes situational.

Therefore, our data indicate a need for disaster preparedness programs that help people fully recognize their risk and build on their personal strengths and preferences (e.g., "What makes me feel healthy? What does it take for me to be healthy, ready, and resilient? What will help me be resilient the most? What can I do to practice and become resilient in thought, belief, and action? What specific actions am I going to take to develop and follow my own personal resilience plan, in support of these outcomes?"). By providing the opportunity for people to explore the multiple dimensions of quality of life and well-being, in the context of their own lives and health narratives, disaster researchers and practitioners can contribute to the development of truly "integrative disaster resilience."

\section{Limitations}

This study data may not be representative of all New Zealand, and results under current conditions may differ. Awareness and acceptance of Wellington's disaster riskscape is higher now than when this survey was administered (2008-2009) because of more recent significant earthquakes in New Zealand (2010-2014) and the Samoa and Japan tsunamis (2009 and 2011, respectively).

We were unable to characterize nonrespondents to the survey, and they may be differently prepared than respondents. It also is impossible to predict whether a person will be at home when disaster strikes, if the evacuation kit will be accessible after damage to the home environment, or if a person's current or future behavior will be consistent with indicated survey responses.

To our knowledge, this is the first application of the instruments used in this study in a pre-disaster setting, and thus we are unable to directly compare our results with other studies. The nature of the epidemiologic cross-sectional study design does not allow the interpretation of more than the strength and direction of relationships among variables and the contribution of an independent variable to explaining the variance in observed results.

\section{Conclusions}

This study explored potential linkages and pathways for building resiliency in the general adult population of Wellington, New Zealand, by examining relationships between QoL and engagement in disaster preparedness. The data show that, despite above-average well-being and widespread hazard awareness, as a whole, people were not prepared for disaster and misperceived the 
nature of risk, readiness, and resilience. We found more similarities than differences in QoL, well-being, and preparedness, regardless of age and gender. Moreover, our data indicate that health-related QoL and global wellbeing were neither profound barriers to nor strong predictors of preparedness. The data, however, reveal a rarely considered dimension for building readiness: a sense of meaning was positively associated with preparedness and had the strongest positive effect among all the variables analyzed here. By nature of the study's cross-sectional design, these observed results may vary over time and repeated sampling with higher response rates. Additional research could yield greater insight into the continuity or changes over time in these associations between wellbeing and preparedness.

All people need to prepare, and preparedness messages that address the layers of risk and resources for personal readiness and adaptation are vital. Preventive disaster research is valuable for finding effective pathways for building resilience. The evidence base contributed by this study indicates that interventions should generally focus on assisting individuals, rather than targeting specific groups; disaster consequences can easily overwhelm sociodemographic boundaries, and people have deeply personal expressions of resilient well-being. Certainly, tailored interventions will continue to be needed and important for those with heightened vulnerability to the compounding consequences of disaster. This research provides evidence, however, that everyone is vulnerable in Wellington, everyone needs greater engagement in evacuation planning and preparedness actions, and it is critical for everyone to think of being prepared, ready, and resilient as more than surviving.

Social and community groups and their sharing of preparedness information can facilitate program delivery and processing of these preparedness action messages $[48,82]$. Moreover, we further argue that delivering preparedness content with broad-brush strokes to the general population on how to be cognitively ready in thought ("I have the fundamental awareness that the threat is present, and it can happen to $m e$ "); affectively ready in belief ("feelings are natural reactions to loss, and I have multidimensional strengths and resources to manage them"); and behaviorally ready in action ("I am building my resources and capacities now to respond and positively adapt for my own unique situation) can additionally promote integrative resilience in all timeframes - prior to, during, and postdisaster.

Clearly, many continuums of comprehension, acceptance, and action overlap within a given community. All disasters are "local"; therefore, solutions must make fundamental sense, must reflect salient dimensions of physical, mental, emotional, social, spiritual, and global well-being for the residents, and must be relevant to their riskscapes.
Preventive health models [165-170] are natural vehicles for promoting readiness. They also complement emergency management policies and practices. Coupling these two well-established paradigms in New Zealand can create conditions that help people build personal resources for facing future adversity and engaging meaningfully in preparedness. Empowering individuals to transcend readiness barriers by engaging in health-promoting actions can inspire greater resilient well-being. From these personal successes will arise community partnership opportunities and the potential to amplify the emergence of disaster prevention and resiliency from local to global levels.

\section{Additional files}

Additional file 1: Table SA1. Type of preparedness activity and level of engagement (\%), at Stages of Change level of measurement.

Additional file 2: Table SA2. Type of preparedness activity and level of engagement (\%), at dichotomized level of measurement.

Additional file 3: Table SA3. Associations among health-related quality of life, subjective well-being, and preparedness activity (Stages of Change).

Additional file 4: Table SA4. Associations among health-related quality of life, subjective well-being, and preparedness activity (intention vs action).

\section{Abbreviations}

ANOVA: Analysis of variance; DRR: Disaster risk reduction; HrQoL: Healthrelated quality of life; QoL: Quality of life; WHO: World Health Organization.

\section{Competing interests}

The authors declare that they have no competing interests.

\section{Authors' contributions}

MEG conceived of the study, selected the design, developed the survey questionnaire, collected the sample data, coordinated the study and survey administration, performed all data entry, data handling, and statistical analyses, and drafted the manuscript. RCK and JAS participated in the conception of the study, its design and coordination, development of the survey instrument and sampling and analyses plans, data analyses, and in the writing of the manuscript. All authors read and approved the final manuscript.

\section{Authors' information}

MEG has a PhD in Health Sciences, a Master of Science in Geology, and a Postgraduate Certificate in Public Health Preparedness, Response, and Recovery. She is a licensed professional geologist and Fellow of the Geological Society of America. She is currently a Postdoctoral Research Fellow at Mayo Clinic. RCK has a PhD in Psychology and is an Associate Professor in Health Sciences at the University of Canterbury. JAS has a PhD in Mathematical Statistics and is a Professor of Oncology and Biostatistics at Mayo Clinic.

\section{Acknowledgements}

This study was conducted in New Zealand at the University of Canterbury, Christchurch, and at GNS Science, Lower Hutt. This was made possible in part through the sponsorship and financial support of University of Canterbury College of Education and School of Health Sciences; GNS Science/Massey University Joint Centre for Disaster Research; New Zealand Earthquake Commission (EQC Research Grant No. 08/U544); New Zealand Ministry of Education; and Mayo Clinic (United States).

The design and conduct of this study benefited from substantial expertise shared by the following individuals. Earthquake Commission (New Zealand): Hugh A. Cowan, PhD. GNS Science/Massey University Joint Centre for Disaster Research (New Zealand): David M. Johnston, PhD. Mayo Clinic (United States): Timothy J. Beebe, PhD; Victor M. Montori, MD; Jennifer St. Sauver, PhD; and Kristin S. Vickers Douglas, PhD, LP. Southern California 
Permanente Medical Group (United States): Steven J. Jacobsen, MD, PhD. Victoria University of Wellington (New Zealand): John McClure, PhD. We gratefully acknowledge L. Joseph Melton III, MD (Mayo Clinic), for his review and valuable comments during the preparation of this article. We extend our deep appreciation to the participants who generously gave their time and shared their experiences and insights for this research.

\section{Author details}

'Department of Health Sciences Research, Mayo Clinic, 200 First St SW, Rochester, MN, USA. ${ }^{2}$ School of Health Sciences, College of Education, University of Canterbury, Christchurch, New Zealand.

Received: 13 February 2014 Accepted: 13 May 2014 Published: 9 June 2014

\section{References}

1. Economic and Social Commission for Asia and the Pacific (ESCAP), United Nations Office for Disaster Risk Reduction (UNISDR): Reducing vulnerability and exposure to disasters: the Asia-Pacific disaster report, 2012. Available from. 2012 [http://www.unescap.org/idd/pubs/Asia-Pacific-DisasterReport-2012.pdf]

2. Muller-Mahn D: (Ed): The spatial dimension of risk: how geography shapes the emergence of riskscapes. New York (NY): Routledge; 2013.

3. Officials' Committee for Domestic and External Security Coordination (ODESC): National hazardscape report. Wellington (New Zealand): Officials' Committee for Domestic and External Security Coordination; 2007.

4. Ministry of Health $(\mathrm{MOH})$ : National health emergency plan: guiding principles for emergency management planning in the health and disability sector. Wellington (New Zealand): Ministry of Health; 2008.

5. Ministry of Civil Defence and Emergency Management (CDEM: The guide to the national civil defence emergency management plan, 2006. Wellington (New Zealand): Ministry of Civil Defence and Emergency Management; 2006.

6. Berryman KR, Cochran UA, Clark KJ, Biasi GP, Langridge RM, Villamor P: Major earthquakes occur regularly on an isolated plate boundary fault. Science 2012, 336(6089):1690-1693.

7. Wallace LM, Reyners M, Cochran U, Bannister S, Barnes PM, Berryman K, Downes G, Eberhart-Phillips D, Fagereng A, Ellis S, Nicol A, McCaffrey R, Beavan RJ, Henrys S, Sutherland R, Barker DHN, Litchfield N, Townend J, Robinson R, Bell R, Wilson K, Power W: Characterizing the seismogenic zone of a major plate boundary subduction thrust: Hikurangi Margin, New Zealand. Geochem Geophys Geosyst 2009, 10(10):1-32. doi:10.1029/2009GC002610

8. Power W: Review of tsunami hazard in New Zealand (2013 update). In GNS Science Consultancy Report 2013/131. Lower Hutt (New Zealand): GNS Science; 2013.

9. GeoNet: Canterbury Quakes. [http://info.geonet.org.nz/display/home/ Canterbury+Quakes]

10. Bannister S, Gledhill K: Evolution of the 2010-2012 Canterbury earthquake sequence. New Zeal J Geol Geop 2012, 55(3):295-304.

11. Canterbury Earthquakes Royal Commission: The Canterbury earthquake sequence and implications for seismic design levels. Wellington (New Zealand): Crown; 2011. Available from: [http://canterbury.royalcommission. govt.nz/documents-by-key/2011-09-2349]

12. New Zealand Police: Christchurch earthquake. [http://www.police.govt.nz/ major-events/previous/christchurch-earthquake]

13. The Earthquake Commission (EQC): Canterbury earthquakes. [http://www.eqc.govt.nz/Canterbury]

14. Berryman K, Gerstenberger M, Webb T, Villamor P, Massey C, Fursman L: The Canterbury earthquake sequence of 2010-2011, New Zealand: a review of seismology, damage observations and consequences. Trebol 2012, 62:18-37.

15. Newell J, Beaven S, Johnston DM: Population movements following the 2010-2011 Canterbury earthquakes: summary of research workshops November 2011 and current evidence. GNS Miscellaneous Series 44; 2013 [Internet] [cited 2013 Nov 20]. Available from: [http://www.massey.ac.nz/ massey/fms/Colleges/College\%20of\%20Humanities\%20and\%20Social\% 20Sciences/Psychology/Disasters/pubs/GNS/2012/Misc_Series_44.pdf]

16. Bray JD, O'Rourke JD, Cubrinovski M, Zupan JD, Jeon S-S, Taylor M, Toprak S, Hughes M, van Ballegooy S, Bouziou D: Liquefaction impact on critical infrastructure in Christchurch. Reston (VA): U.S: Geological Survey; 2013.
Available from: [http://earthquake.usgs.gov/research/external/reports/ G12AP20034.pdf]

17. Ardagh MW, Richardson SK, Robinson V, Than M, Gee P, Henderson S, Khodaverdi L, McKie J, Robertson G, Schroeder PP, Deely JM: The initial health-system response to the earthquake in Christchurch, New Zealand, in February, 2011. Lancet 2012, 379(9831):2109-2115. Epub 2012 Apr 16

18. Tovaranonte P, Cawood TJ: Impact of the Christchurch earthquakes on hospital staff. Prehosp Disaster Med 2013, 28(3):245-250. Epub 2013 Mar 26.

19. Parker M, Steenkamp D: The economic impact of the Canterbury earthquakes. Reserve Bank NZ Bull 2012, 75(3):13-25. Available from: [http://www.rbnz.govt.nz/research_and_publications/reserve_bank_bulletin/ 2012/2012sep75_3.pdf]

20. Doyle L, Noy I: The short-run nationwide macroeconomic effects of the Canterbury earthquakes. 2013 [Internet] [2013 Mar; cited 2013 Nov 20]. Available from: [http://researcharchive.vuw.ac.nz/handle/10063/2677]

21. GeoNet: Cook Strait earthquakes and Eketahuna earthquake. [http://info.geonet.org.nz/display/home/Latest+News]

22. Langridge $\mathrm{R}$, Van Dissen $\mathrm{R}$, Rhoades $\mathrm{D}$, Villamor $\mathrm{P}$, Little $\mathrm{T}$, Litchfield N, Clark $K$, Clark D: Five thousand years of surface ruptures on the Wellington Fault, New Zealand: implications for recurrence and fault segmentation. Bull Seismol Soc Am 2011, 101:2088-2107.

23. Grapes R, Downes G: The 1855 Wairarapa, New Zealand, earthquake: analysis of historical data. Bull New Zealand Natl Soc Earthquake Eng 1997, 30(4):371-68.

24. Van Dissen R, Barnes P, Beavan J, Cousins J, Dellow G, Francois-Holden C, Fry B, Langridge R, Litchfield N, Little T, McVerry G, Ninis D, Rhoades D, Robinson R, Saunders W, Villamor P, Wilson K, Barker P, Berryman K, Benites R, Brackley H, Bradley BA, Carne R, Cochran U, Hemphill-Haley M, King A, Lamarche G, Palmer $\mathrm{N}$, Perrin N, Pondard N, et al: It's Our Fault: better defining earthquake risk in Wellington. In Geologically Active: Proceedings of the 11th IAEG Congress. Auckland, New Zealand: 2010:5-10. Available from: [http://www.gns.cri.nz/ Home/IOF/It-s-Our-Fault/Abstract-Van-Dissen-IAEG]

25. Cousins WJ: Earthquake damage and casualties due to large earthquakes impacting Wellington region. In GNS Science Report 2013/41. Lower Hutt (New Zealand): GNS Science; 2013.

26. Cousins WJ: Wellington without water: impacts of large earthquakes. In GNS Science Report 2012/30. Lower Hutt (New Zealand): GNS Science; 2013.

27. Cousins WJ, King AB, Kanga M: Accumulated losses from sequences of earthquakes: implications for risk modeling. In Proceedings of the 15th World Conference on Earthquake Engineering. Lisbon, Portugal: 2012:24-28. Available from: [http://www.iitk.ac.in/nicee/wcee/article/WCEE2012 3812.pdf]

28. Wright KC, Johnston DM: Post-earthquake sheltering needs: how loss of structures and services affects decision making for evacuation. In 2010 New Zealand Society for Earthquake Engineering Conference Proceedings. Wellington, New Zealand: 2010:21-23.

29. Bartels SA, VanRooyen MJ: Medical complications associated with earthquakes. Lancet 2012, 379(9817):748-757. Epub 2011 Nov 4. Erratum in: Lancet 2012, 379 (9817):712.

30. Doocy S, Daniels A, Packer C, Dick A, Kirsch TD: The human impact of earthquakes: a historical review of events 1980-2009 and systematic literature review. PLoS Curr 2013, 16:5

31. Doocy S, Daniels A, Dick A, Kirsch TD: The human impact of tsunamis: a historical review of events 1900-2009 and systematic literature review. PLOS Curr 2013, 16:5.

32. Mani A, Mullainathan S, Shafir E, Zhao J: Poverty impedes cognitive function. Science 2013, 341(6149):976-980.

33. Helton WS, Head J: Earthquakes on the mind: implications of disasters for human performance. Hum Factors 2012, 54(2):189-194

34. Tempesta D, Curcio G, De Gennaro L, Ferrara M: Long-term impact of earthquakes on sleep quality. PLoS One 2013, 8(2):e55936. Epub 2013 Feb 13

35. Wen J, Shi YK, Li YP, Yuan P, Wang F: Quality of life, physical diseases, and psychological impairment among survivors 3 years after Wenchuan earthquake: a population based survey. PLoS One 2012, 7(8):e43081. Epub 2012 Aug 21

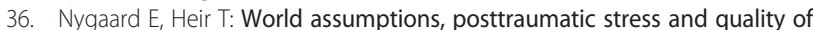
life after a natural disaster: a longitudinal study. Health Qual Life Outcomes 2012, 10:76.

37. Rubonis AV, Bickman L: Psychological impairment in the wake of disaster: the disaster-psychopathology relationship. Psychol Bull 1991, 109(3):384-399. 
38. Houston JB, Pfefferbaum B, Reyes G, Wyche KF, Jones RT, Yoden M: Domestic disaster displacement manual (3D): working with people who have been displaced. Oklahoma City, Oklahoma: Terrorism and Disaster Center at the University of Oklahoma Health Sciences Center; 2009.

39. Whiteford LM, Tobin GA: Saving lives, destroying livelihoods: emergency evacuation and resettlement policies in Ecuador. In Unhealthy health policy: a critical anthropological examination. Edited by Castro A, Singer M. Walnut Creek (CA): AltaMira Press; 2004:189-202.

40. Levac J, Toal-Sullivan D, O'Sullivan TL: Household emergency preparedness: a literature review. J Community Health 2012, 37(3):725-733.

41. Mileti D: Disasters by design: A reassessment of natural hazards in the United States. Washington, DC: National Academies Press; 1999.

42. United Nations Office for Disaster Risk Reduction: Global assessment report on disaster risk reduction (2011): revealing risk, redefining development. Geneva (Switzerland): United Nations Office for Disaster Risk Reduction (UNISDR); 2011.

43. International Strategy for Disaster Reduction: 2009 UNISDR terminology on disaster risk reduction. Geneva (Switzerland): United Nations International Strategy for Disaster Reduction (UNISDR); 2009.

44. Alexander DE: Resilience and disaster risk reduction: an etymological journey. Nat Hazards Earth Syst Sci 2013, 13:2707-2716.

45. Martin-Breen P, Anderies JM: Resilience: a literature review [Internet]. New York (NY): The Rockfeller Foundation; 2011. Available from: [http://www.rockefellerfoundation.org/blog/resilience-literature-review]

46. Sundermann L, Schelske O, Hausmann P: Mind the risk: a global ranking of cities under threat from natural disasters. Zurich, Switzerland: Swiss Re; 2013. Available from: [http://media.swissre.com/documents/Swiss_Re_Mind_the_risk.pdf]

47. Lemyre L, Clement M, Corneil W, Craig L, Boutette P, Tyshenko M, Karyakina N, Clarke R, Krewski D, GAP-Sante Research Team: A psychosocial risk assessment and management framework to enhance response to CBRN terrorism threats and attacks. Biosecur Bioterror 2005, 3(4):316-330.

48. Lindell MK, Perry RW: The protective action decision model: theoretical modifications and additional evidence. Risk Anal 2012, 32(4):616-632. Epub 2011 Jun 20

49. Sorensen $\mathrm{JH}$ : When shall we leave? Factors affecting the timing of evacuation departures. Int J Mass Emerg Disasters 1991, 9(2):153-165.

50. Slovic P, Peters E, Finucane ML, Macgregor DG: Affect, risk, and decision making. Health Psychol 2005, 24(Suppl 4):S35-S40.

51. Rohrmann B: A socio-psychological model for analyzing risk communication processes. Aust J Disaster Trauma Stud 2000, 2:150-166

52. Almedom AM, Tumwine JK: Resilience to disasters: a paradigm shift from vulnerability to strength. Afr Health Sci 2008, 1(Suppl 8):S1-S4.

53. Almedom AM: Resilience: outcome, process, emergence, narrative (OPEN) theory. On the Horizon 2013, 21(1):15-23.

54. National Research Council (US): Positive health: resilience, recovery, primary prevention, and health promotion. [Internet]. In Committee on Future Directions for Behavioral and Social Sciences Research at the National Institutes of Health. Edited by Singer BH, Ryff CD. Washington (DC): National Academies Press; 2001. Available from: [http://www.ncbi.nlm.nih.gov/books/ NBK43790/]

55. The UN Special Representative of the Secretary-General for Disaster Risk Reduction: Proposed elements for consideration in the development of the post-2015 framework for disaster risk reduction. Geneva (Switzerland): United Nations Office for Disaster Risk Reduction; 2013. Available from: [http://www.preventionweb.net/files/35888_srsgelements.pdf]

56. Lavell A, Kaskrey A: The future of disaster risk management: an on-going discussion. San Jose (Costa Rica): Latin American Social Science Faculty [FLACSO] and United Nations Office for Disaster Risk Reduction [UNISDR]; 2013. Available from: [http://www.unisdr.org/we/inform/publications/35715]

57. World Health Organization: Online consultation briefing paper: health and the post-2015 framework for reducing risks of disasters. Geneva (Switzerland): World Health Organization; 2013. Available from: [http://www.who.int/hac/ events/2013/online_consultation_background_paper_15april2013.pdf]

58. Ministry of Civil Defence and Emergency Management (CDEM): New Zealand national progress report on the implementation of the Hyogo Framework for Action (2011-2013). Wellington (New Zealand): Ministry of Civil Defence and Emergency Management; 2013. Available from: [http:// www.preventionweb.net/files/28748_nzl_NationalHFAprogress_2011-13.pdf]

59. UN-Habitat: UN-Habitat announces ten partner cities for the city resilience profiling programme [Internet]. Nairobi (Kenya): UN-Habitat; 2013. Available from: [http://www.preventionweb.net/english/professional/news/v.php?id=32500]
60. Norris FH, Friedman MJ, Watson PJ, Byrne CM, Diaz E, Kaniasty K: 60,000 disaster victims speak: Part I: an empirical review of the empirical literature, 1981-2001. Psychiatry 2002, 65(3):207-239.

61. Bonanno GA, Brewin CR, Kaniasty K, LaGreca AM: Weighing the costs of disaster: consequences, risks, and resilience in individuals, families, and communities. Psychol Sci Public Interest [Internet] 2010, [cited 2013 Nov 19]. Available from: [http://www.psychologicalscience.org/journals/pspi/pspi_10_4.pdf]

62. Bethel JW, Foreman AN, Burke SC: Disaster preparedness among medically vulnerable populations [Internet]. Am J Prev Med 2011 40(2):139-143

63. Uscher-Pines L, Hausman AJ, Powell S, DeMara P, Heake G, Hagen MG: Disaster preparedness of households with special needs in southeastern Pennsylvania. Am J of Prev Med 2009, 37(3):227-230.

64. Van den Berg B, van der Velden PG, Yzermans J, Stellato RK, Grievink L: Health-related quality of life and mental health problems after a disaster: are chronically ill survivors more vulnerable to health problems? Qual Life Res 2006, 15:1571-1576.

65. Ablah E, Konda J, Kelley CL: Factors predicting individual emergency preparedness: a multi-state analysis of 2006 BRFSS data. Biosecur Bioterror 2009, 7:317-330.

66. Mokdad AH, Mensah GA, Posner SF, Reed E, Simoes EJ, Engelgau MM, And the Chronic Diseases and Vulnerable Populations in Natural Disasters Working Group: When chronic conditions become acute: prevention and control of chronic diseases and adverse health outcomes during natural disasters. Prev Chronic Dis 2005, [serial online] 2005. Available from: [http://www.cdc.gov/pcd/issues/2005/nov/05_0201.htm]

67. ORC/Macro: Methodological considerations and key findings in preparedness research. In Citizen Preparedness Review: A Quarterly Review of Citizen Preparedness Research. Washington, DC: US Department of Homeland Security; 2005.

68. Rapp CA, Goscha RJ: The strengths model: a recovery-oriented approach to mental health services (3rd ed). New York: Oxford University Press; 2012

69. Duckworth AL, Steen TA, Seligman MEP: Positive psychology in clinical practice. Ann Rev Clin Psychol 2005, 1:629-651.

70. Aspinwall LG, Staudinger UM: A psychology of human strengths: some central issues of an emerging field. In A psychology of human strengths: fundamental questions and future directions for a positive psychology. Edited by Aspinwall LG, Staudinger UM. Washington (DC): American Psychological Association; 2003.

71. Norris FH, Tracy M, Galea S: Looking for resilience: understanding the longitudinal trajectories of responses to stress. Soc Sci Med 2009, 68(12):2190-2198. Epub 2009 May 4.

72. Norris FH, Stevens SP, Pfefferbaum B, Wyche KF, Pfefferbaum RL: Community resilience as a metaphor, theory, set of capacities, and strategy for disaster readiness. Am J Community Psychol 2008, 41(1-2):127-150.

73. Tedeschi RG, Kilmer RG, Ryan P: Assessing strengths, resilience, and growth to guide clinical interventions. Prof Psychol: Res Pract 2005, 36(3):2307.

74. Harrop E, Addis S, Elliott E, Williams G: Resilience, coping and salutogenic approaches to maintaining and generating health: a review [Internet]. Cardiff: Wales, UK: Cardiff Institute of Society, Health, and Ethics; 2006. Available from: [http://www.nice.org.uk/nicemedia/live/11868/44523/44523.pdf]

75. Lindstrom B, Eriksson M: Salutogenesis. J Epidemiol Community Health 2005, 59(6):440-442

76. The World Health Organization Quality of Life assessment (WHOQOL): Position paper from the World Health Organization. Soc Sci Med 1995, 41(10):1403-1409.

77. World Health Organizaton: WHO definition of health, Preamble to the Constitution of the World Health Organization as adopted by the International Health Conference, New York, 19-22 June, 1946. In Official Records of the World Health Organization. 2nd edition. 2007:100.

78. Sagi-Schwartz A, Bakermans-Kranenburg MJ, Linn S, Van ljzendoorn MH: Against all odds: genocidal trauma is associated with longer life-expectancy of the survivors. PLoS One 2013, 24; 8(7):e69179.

79. Hobfoll SE, Hall BJ, Canetti-Nisim D, Galea S, Johnson RJ, Palmieri PA: Refining our understanding of traumatic growth in the face of terrorism: moving from meaning cognitions to doing what is meaningful. Appl Psychol 2007, 56(30):345-366.

80. Deci EL, Ryan RM: Intrinsic motivation and self-determination in human behavior. New York (NY): Plenum; 1985.

81. Lindell MK, Perry RW: Household adjustment to earthquake hazard: a review of research. Environ Behav 2000, 32(4):461-501. 
82. Wood MM, Mileti DS, Kano M, Kelley MM, Regan R, Bourque LB: Communicating actionable risk for terrorism and other hazards. Risk Anal 2012, 32(4):601-615 [cited 9 April 2014].

83. Pfefferbaum B, Flynn BW, Schonfeld D, Brown LM, Jacobs GA, Dodgen D, Donato D, Kaul RE, Stone B, Norwood AE, Reissman DB, Herrmann J, Hobfoll SE, Jones RT, Ruzek JI, Ursano RJ, Taylor RJ, Lindley D: The integration of mental and behavioral health into disaster preparedness, response, and recovery. Disaster Med Public Health Prep 2012, 6:60-66.

84. Evidence Aid Priority Setting Group (EA): Prioritization of themes and research questions for health outcomes in natural disasters, humanitarian crises or other major healthcare emergencies. PLoS Curr 2013, 16:5.

85. Kayabu B, Clarke M: The use of systematic reviews and other research evidence in disasters and related areas: preliminary report of a needs assessment survey. PLoS Curr 2013, 22:5.

86. Windle G, Bennett KM, Noyes J: A methodological review of resilience measurement scales. Health Qual Life Outcomes 2011, 9:8.

87. Mokkink LB, Terwee CB, Stratford PW, Alonso J, Patrick DL, Riphagen I, Knol $D L$, Bouter $L M$, De Vet HCW: Evaluation of the methodological quality of systematic reviews of health status measurement instruments. Qual Life Res 2009, 18(3):313-333. Epub 2009 Feb 24.

88. Statistics New Zealand: New Zealand general social survey: 2012 [Internet]. Wellington (New Zealand): Statistics New Zealand; Available from: [http://www.stats.govt.nz/browse_for_stats/people_and_communities/ Households/nzgss_HOTP2012.aspx]

89. Human Potential Center: Sovereign wellbeing index: New Zealand's first measure of wellbeing [Internet]. Auckland (New Zealand): Auckland University of Technology; 2013. Available from: [http://www.mywellbeing.co.nz/mw/ report/sovereign-wellbeing-index-2013-report.pdf]

90. Quality of life survey 2012: Six councils report [Internet]. Wellington (New Zealand): Quality of Life; 2012. Available from: [http://www. qualityoflifeproject.govt.nz/pdfs/Quality_of_Life_2012.pdf]

91. Ministry of Health (MOH): The health of New Zealand adults 2011/12: key findings of the New Zealand health survey [Internet]. Wellington (New Zealand): Ministry of Health; 2012. Dec [cited 2013 Nov 20]. Available from: [http://www.health.govt.nz/publication/health-new-zealand-adults-2011-12]

92. Jamieson $\mathrm{K}$ : A collaborative approach to developing and using quality of life indicators in New Zealand's largest cities. In Community quality-of-life indicators: social indicators research series. Edited by Sirgy MJ, Rahtz D, Dong-Jin L. Dordrecht (The Netherlands): Springer; 2004. Available from: [http://link.springer.com/chapter/10.1007/978-1-4020-2202-9_4]

93. Strine TW, Neff $L$, Crawford S: Health-related quality of life domains and household preparedness for public health emergencies: behavioral risk factor surveillance system, 2006-2010. Disaster Med Public Health Prep 2013, 7:191-200.

94. Ware J Jr, Kosinski M, Keller SD: A 12-Item Short-Form Health Survey: construction of scales and preliminary tests of reliability and validity. Med Care 1996, 34(3):220-233.

95. Antonovsky A: Unraveling the mystery of health: how people manage stress and stay well. San Francisco: Jossey Bass; 1987.

96. Boyd-Wilson BM: A measure of serenity: a fresh look at well-being. In Advances in Psychology Research. Edited by Columbus AM. Hauppauge (NY): Nova; 2006.

97. Boyd-Wilson BM: Serenity: much more than just feeling calm. In Advances in Psychology Research. Edited by Shohov SP. Hauppauge (NY): Nova; 2004.

98. Hawthorne G: Measuring social isolation in older adults: development and initial validation of the friendship scale. Social Indicators Res 2006, 77(3):521-548

99. Diener E, Emmons RA, Larsen RJ, Griffin S: The Satisfaction With Life Scale. J Pers Assess 1985, 49(1):71-75.

100. Australian Centre on Quality of Life Directory of Instruments. [http://www.deakin.edu.au/research/acqol/instruments/]

101. The Quality of life Forms Bank. [http://www.qolpro.org/qolother1.html]

102. Johnston DM, Paton D, Saunders W, Coomer MA, Frandsen M, Barton D: Community awareness and understanding of tsunami risk in Western Australia, Queensland and New South Wales: tabulated results of a 2008-2009 survey. In GNS Science Report 2009/16. Lower Hutt (New Zealand): GNS Science; 2009.

103. Davis M, Johnston D, Becker J, Leonard G, Coomer M, Gregg C: Risk perceptions and preparedness: Mt Rainier 2006 community assessment tabulated results. In GNS Science Report 2006/17. Lower Hutt (New Zealand): GNS Science; 2006.
104. Leonard G, Johnston DM, Paton D: Analysis of Te Anau residents' impacts, awareness and preparedness following the 2003 Fiordland earthquake. In Institute of Geological and Nuclear Sciences science report 2004/37. Lower Hutt (New Zealand): Institute of Geological and Nuclear Sciences; 2004.

105. Johnston D, Leonard G, Bell R, Stewart C, Hickman M, Thomson J, Kerr J, Glassey P: Tabulated results of the 2003 National Coastal Community Survey. In Institute of Geological and Nuclear Sciences science report 2003/35. Lower Hutt (New Zealand): Institute of Geological and Nuclear Sciences; Available from: [http://www.gw.govt.nz/assets/council-publications/ Environment\%20Management_20040420_163833.pdf]

106. Statistics New Zealand List of Classifications and Statistical Standards. [http:// www.stats.govt.nz/methods/classifications-and-standards/classificationrelated-stats-standards.aspx]

107. Ministry of Civil Defence and Emergency Management (MCDEM): Tsunami advisory warning: supporting plan SP 01/09 [updated]. Wellington (New Zealand): MCDEM; 2012. Available from: [http://www.civildefence.govt.nz/ memwebsite.nsf/Files/Tsunami-advisory-warning-SP01-May12-web/\$file/ Tsunami-advisory-warning-SP01-May12.pdf]

108. Ministry of Civil Defence and Emergency Management (MCDEM): Wellington earthquake national initial response plan. Wellington, (New Zealand): Ministry of Civil Defence and Emergency Management; 2012. Available from: [http://www.civildefence.govt.nz/memwebsite.nsf/Files/Wellington-EQ-plan/ \$file/WellingtonEQplan.pdf]

109. Ministry of Civil Defence and Emergency Management (MCDEM): Mass evacuation planning: director's guidelines for Civil Defence Emergency Management (CDEM) Groups (DGL 07/08). Wellington, (New Zealand) Ministry of Civil Defence and Emergency Management; 2008. Available from: [http://www.civildefence.govt.nz/memwebsite.nsf/Files/ Director_Guidelines/\$file/Mass-evacu-planningDGL07-08.pdf]

110. Power and Precision, version 2. Englewood (NJ): Biostat; 2000 [http://www.power-analysis.com]

111. Antonovsky A: The structure and properties of the sense of coherence scale. Soc Sci Med 1993, 36(6):725-733.

112. Prochaska JO, DiClemente CC: Transtheoretical therapy: toward a more integrative model of change. Psychotherapy: Theory Res Pract 1982, 19(3):276-288.

113. Prochaska JO, DiClemente CC: Stages and processes of self-change of smoking: toward an integrative model of change. J Consult Clin Psychol 1983, 51(3):390-395.

114. Cohen J: Statistical power analysis for the behavioral sciences. Hillsdale (NJ): L Erlbaum Associates; 1988.

115. Eriksson M, Lindstrom B: Antonovsky's sense of coherence scale and its relation with quality of life: a systematic review. J Epidemiol Community Health 2007, 61(11):938-944.

116. Eriksson M, Lindstrom B: Antonovsky's sense of coherence scale and the relation with health: a systematic review. J Epidemiol Community Health 2006, 60(5):376-381.

117. Scott KM, Tobias MI, Sarfati D, Haslett SJ: SF-36 health survey reliability, validity and norms for New Zealand. Aust N Z J Public Health 1999, 23(4):401-406

118. Hawthorne G: Perceived social isolation in a community sample: its prevalence and correlates with aspects of peoples' lives. Soc Psychiatry Psychiatr Epidemiol 2008, 43(2):140-150. Epub 2007 Nov 9.

119. Diener E, Lucas RE, Oishi S: Subjective well-being: the science of happiness and life satisfaction. In Handbook of Positive Psychology. Edited by Snyder CR, Lopez SJ. New York (NY): Oxford University Press; 2002.

120. Diener E: Subjective well-being: the science of happiness and a proposal for a national index. Am Psychol 2000, 55(1):34-43.

121. Statistics New Zealand: Census 2006. Wellington (New Zealand): Statistics New Zealand; 2006. Available from: [http://www.stats.govt.nz/Census.aspx]

122. The New Zealand Film Archive: Aftershock. Wellington (New Zealand): New Zealand Film Archive; 2008. Available from: [http://www.filmarchive.org.nz/ the-catalogue/media/aftershock-f110062]

123. Ministry of Civil Defence and Emergency Management (MCDEM): Household emergency checklist. Wellington (New Zealand): Ministry of Civil Defence and Emergency Management; 2013. Available from: [http://www.civildefence. govt.nz/memwebsite.nsf/Files/Public_Education_Resources_NPEP06/\$file/ Emergency_checklist_10\%5B1\%5D.pdf]

124. The Earthquake Commission (EQC): Kits and plans. Wellington (New Zealand): Earthquake Commission; 2013. Available from: [http://www.eq-iq. co.nz/be-prepared/kits-plans] 
125. Ministry of Health (MOH): Protecting your health in an emergency: preparing yourself and your family for a disaster. Wellington (New Zealand): Ministry of Health; 2006. Available from: [https://www.health.govt.nz/system/files/ documents/publications/protecting-your-health-emergency.pdf]

126. Ministry of Civil Defence and Emergency Management (MCDEM): Campaign monitoring research 2013. Wellington (New Zealand): Ministry of Civil Defence and Emergency Management; 2013. Available from: [http://www. civildefence.govt.nz/memwebsite.nsf/Files/MCDEM-Campaign-MonitoringResearch-July-2013/\$file/Get-Ready-Get-Thru-report-Jul-2013.pdf]

127. Statistics New Zealand: How prepared are New Zealanders for a natural disaster? Results from the 2010 General Social Survey. Wellington (New Zealand): Statistics New Zealand; 2012. Available from: [http://www.stats. govt.nz/browse_for_stats/people_and_communities/Households/naturaldisaster-how-prepared-nzers.aspx]

128. Johnston D, Becker J, McClure J, Paton D, McBride S, Wright K, Leonard G, Hughes M: Community understanding of, and preparedness for, earthquake and tsunami risk in Wellington, New Zealand. In Cities at risk: living with perils in the 21st century, Advances in natural and technological hazards research series. Edited by Joffe H, Rossetto T, Adams J. The Netherlands: Springer; 2013:131-148. 33.

129. McClure J, Johnston D, Henrich L: Changes in preparedness and earthquake risk perception: lessons from the 2010 and 2011 Canterbury earthquakes. Wellington (New Zealand): Earthquake Commission; 2013. Available from: [http://www.eqc.govt.nz/research/research-papers/preparedness-riskperception-canterbury-2010-2011]

130. Sorensen $\mathrm{JH}$ : Hazard warning systems: review of 20 years of progress. Nat Hazards Rev 2000, 1(2):119-125.

131. Sorensen JH, Vogt Sorensen B: Community processes: warning and evacuation. In Handbook of disaster research. Edited by Rodriguez $\mathrm{H}_{\text {, }}$ Quarantelli EL, Dynes R. New York (NY): Springer; 2007.

132. McClure J, Sibley CG: Framing effects on disaster preparation: is negative framing more effective? Aust J Disaster Trauma Studies 2011, 1:1-10.

133. McClure J, White J, Sibley CG: Framing effects on preparation intentions: distinguishing actions and outcomes. Disaster Prev Manage 2009, 18(2):187-199.

134. Walton D, Smith K: Survival confidence of New Zealanders in outdoor and post-earthquake situations. Aust J Emerg Manage 2009, 24(3):38-43.

135. Spittal MJ, McClure J, Siegert RJ, Walkey FH: Predictors of two types of earthquake preparation: survival activities and mitigation activities. Environ Behav 2008, 40(6):798-817.

136. Spittal MJ, Walkey FH, McClure J, Siegert RJ, Ballantyne KE: The Earthquake Readiness Scale: the development of a valid and reliable unifactorial measure. Nat Hazards 2006, 39(1):15-29.

137. Currie C-S, Enjamio J, Girardo DO, Hensel C: Tsunami awareness and preparedness in the Greater Wellington Region. 2013. Available from: [http://www.wpi.edu/Pubs/E-project/Available/E-project-022713-210752/ unrestricted/WPI_tsunami_awareness_28-2-13_WPI.pdf]

138. Apatu EJI, Gregg CE, Lindell MK, Sorensen J, Hillhouse J, Sorensen B: The September 29, 2009 earthquake and tsunami in American Samoa: a case study of household evacuation behavior and the Protective Action Decision Model. Geophysical Res Abstracts 2012, 14:101. EGU2012.

139. Johnstone W, Lence B: Use of flood, loss, and evacuation models to assess exposure and improve a community tsunami response plan: Vancouver Island. Nat Hazards Rev 2012, 13(2):162-171.

140. Wood NJ, Burton CG, Cutter SL: Community variations in social vulnerability to Cascadia-related tsunamis in the U.S. Pacific Northwest. Nat Hazards 2010, 52(2):369-389.

141. Pincock S: Gaps exist in tsunami preparedness plans. Lancet 2007, 369(9579):2065.

142. Wellington Region Emergency Management Office (WREMO): Community Resilience Strategy. Thorndon (New Zealand): Wellington Region Emergency Management Office; 2012. Available from: [http://www.gw.govt.nz/assets/ Emergencies-Hazards/WREMO/Publications/WREMO-Community-ResilienceStrategy-2012-v1.4.pdf]

143. Wellington Region Emergency Management Office (WREMO): Raising Tsunami Awareness: A Guide for Communities \& Local Governments. Wellington (New Zealand): Wellington Region Emergency Management Office; 2012.

144. Wellington City Council Emergency management. [http://www.wellington. govt.nz/about-wellington/emergency-management]

145. Ministry of Civil Defence and Emergency Management: The way forward: strategic framework for the National CDEM Public Education Programme
2006 - 2015. Wellington (New Zealand): Ministry of Civil Defence and Emergency Management; 2015. Available from: [http://www.civildefence. govt.nz/memwebsite.nsf/wpg_URL/For-the-CDEM-Sector-Public-EducationPublic-Education-Strategy?OpenDocument]

146. Selman L, Speck P, Gysels M, Agupio G, Dinat N, Downing J, Gwyther L, Mashao T, Mmoledi K, Moll T, Sebuyira LM, Ikin B, Higginson IJ, Harding R: 'Peace' and 'life worthwhile' as measures of spiritual well-being in African palliative care: a mixed-methods study. Health Qual Life Outcomes 2013, 11:94

147. Almedom AM: Sense and sensibilities of coherence in disaster mitigation and response [abstract]. In Proceedings of the 4th International Research Seminar on Salutogenesis and Meeting of the International Union for Health Promotion and Education (IUHPE) and Global Working Group on Salutogenesis (GWG-SAL). Sweden: University West Trollhattan; 2011:30-31.

148. Hildon Z, Montgomery SM, Blane D, Wiggins RD, Netuveli G: Examining resilience of quality of life in the face of health-related and psychosocial adversity at older ages: what is "right" about the way we age? Gerontologist 2010, 50(1):36-47. Epub 2009 Jun 23.

149. Durkin J, Joseph S: Growth following adversity and its relation with subjective well-being and psychological well-being. J Loss Trauma 2009, $14: 228-234$.

150. Prochaska JO, DiClemente CC, Norcross JC: In search of how people change: applications to addictive behaviors. Am Psychol 1992, 47(9):1102-1114.

151. Diener E, Sandvik E, Pavot W: Happiness is the frequency, not the intensity, of positive versus negative affect. In Subjective well-being: an interdisciplinary perspective. Edited by Strack F, Argyle M, Schwarz M. New York (NY): Pergamon Press; 1991:119-139.

152. Ke X, Liu C, Li N: Social support and quality of life: a cross-sectional study on survivors eight months after the 2008 Wenchuan earthquake. BMC Public Health 2010, 10:573.

153. Vastfjall D, Peters $E$, Slovic P: Affect, risk perception and future optimism after the tsunami disaster. Judgment Decision Making 2008, 3(1):64-72.

154. Tremblay MA, Blanchard CM, Pelletier LG, Vallerand RJ: A dual route in explaining health outcomes in natural disaster. J App/ Soc Psychol 2006, 36(6):1502-1522.

155. Wang X, Gao L, Zhang H, Zhao C, Shen Y, Shinfuku N: Post-earthquake quality of life and psychological well-being: longitudinal evaluation in a rural community sample in northern China. Psychiatry Clin Neurosci 2000, 54(4):427-433.

156. Norris FH: Frequency and structure of precautionary behavior in the domains of hazard preparedness, crime prevention, vehicular safety, and health maintenance. Health Psychol 1997, 16(6):566-575.

157. Weinstein ND: Effects of personal experience on self-protective behavior. Psychol Bull 1989, 105(1):31-50.

158. Glanz K, Rimer BK, Lewis FM: (Eds): Health behavior and health education: theory, research, and practice. 3rd edition. San Francisco (CA): Jossey-Bass; 2002

159. Heckhausen H, Gollwitzer PM: Thought contents and cognitive functioning in motivational versus volitional states of mind. Motiv Emot 1987, 11:101-120.

160. Breinbauer C, Maddaleno HM, And Pan American Health Organization (PAHO): Youth: Choices and change: promoting healthy behaviors in adolescents. Washington, DC: Pan American Health Organization; 2005.

161. McLeroy KR, Bibeau D, Steckler A, Glanz K: An ecological perspective on health promotion programs. Health Educ Q 1988, 15:351-377.

162. Slovic P, Finucane ML, Peters E, MacGregor DG: Risk as analysis and risk as feelings: some thoughts about affect, reason, risk, and rationality. Risk Anal 2004, 24(2):311-322

163. Slovic $P$, Weber EU: Perceptions of risk posed by extreme events. In Proceedings of the conference on Risk Management Strategies in an Uncertain World: 12-13 Apr 2002. New York (NY): Center for Hazards and Risk Research, Columbia Earth Institute, Wharton School, \& Lamont-Doherty Earth Observatory; 2002.

164. Quarantelli EL: Perceptions and reactions to emergency warnings of sudden hazards. Emmitsburg (MD): National Emergency Training Center; 1984.

165. World Health Organization (WHO): The Bangkok Charter. Health Promot Int 2005, 21(s1):10-14.

166. Ministry of Health $(\mathrm{MOH})$ : The national health promotion: framework and implementation planning guide for screening programmes, National Screening Unit. Wellington (New Zealand): Ministry of Health; 2004.

167. Ministry of Health (MOH): Building on strengths: a new approach to promoting mental health in New Zealand/Aorearoa. Wellington (New Zealand): Ministry of Health; 2002. 
168. Durie M: Te Pae Mahutonga: a model for Maori health promotion. Health Promot Forum NZ Newsletter 1999, 49:2-5.

169. World Health Organization (WHO): The Jakarta Declaration on leading health promotion into the 21st Century. Health Promot Int 1997, 12(4):261-264

170. World Health Organization (WHO): Ottawa Charter for health promotion: an international conference on health promotion, the move towards a new public health. Health Promot Int 1986, 1(4):405.

doi:10.1186/1477-7525-12-85

Cite this article as: Gowan et al:: Building resiliency: a cross-sectional study examining relationships among health-related quality of life, wellbeing, and disaster preparedness. Health and Quality of Life Outcomes 2014 12:85.

\section{Submit your next manuscript to BioMed Central and take full advantage of:}

- Convenient online submission

- Thorough peer review

- No space constraints or color figure charges

- Immediate publication on acceptance

- Inclusion in PubMed, CAS, Scopus and Google Scholar

- Research which is freely available for redistribution 